\title{
320-to-10 Gbit/s all-optical demultiplexing using sum- frequency generation in PPLN waveguide
}

\section{Citation for published version (APA):}

Gomez-Agis, F., Okonkwo, C. M., Álbores Mejia, A., Tangdiongga, E., \& Dorren, H. J. S. (2010). 320-to-10 Gbit/s all-optical demultiplexing using sum-frequency generation in PPLN waveguide. Electronics Letters, 46(14), 1008-1009. https://doi.org/10.1049/el.2010.0075

DOI:

10.1049/el.2010.0075

Document status and date:

Published: 01/01/2010

\section{Document Version:}

Publisher's PDF, also known as Version of Record (includes final page, issue and volume numbers)

\section{Please check the document version of this publication:}

- A submitted manuscript is the version of the article upon submission and before peer-review. There can be important differences between the submitted version and the official published version of record. People interested in the research are advised to contact the author for the final version of the publication, or visit the $\mathrm{DOI}$ to the publisher's website.

- The final author version and the galley proof are versions of the publication after peer review.

- The final published version features the final layout of the paper including the volume, issue and page numbers.

Link to publication

\section{General rights}

Copyright and moral rights for the publications made accessible in the public portal are retained by the authors and/or other copyright owners and it is a condition of accessing publications that users recognise and abide by the legal requirements associated with these rights.

- Users may download and print one copy of any publication from the public portal for the purpose of private study or research.

- You may not further distribute the material or use it for any profit-making activity or commercial gain

- You may freely distribute the URL identifying the publication in the public portal.

If the publication is distributed under the terms of Article 25fa of the Dutch Copyright Act, indicated by the "Taverne" license above, please follow below link for the End User Agreement:

www.tue.nl/taverne

Take down policy

If you believe that this document breaches copyright please contact us at:

openaccess@tue.nl

providing details and we will investigate your claim. 


\section{0-to-10 Gbit/s all-optical demultiplexing using sum-frequency generation in PPLN waveguide}

\author{
F. Gomez-Agis, C.M. Okonkwo, A. Albores-Mejia, \\ E. Tangdiongga and H.J.S. Dorren
}

A 320-to-10 Gbit/s all-optical demultiplexer based on sum-frequency generation in a periodically-poled lithium niobate (PPLN) waveguide is demonstrated. A bit-error-rate of $10^{-9}$ is achieved with a power penalty of $1.5 \mathrm{~dB}$.

Introduction: All-optical demultiplexing (AOD) is an essential function in optical time-division multiplexed (OTDM) systems, which serves to extract base-rate channels from a time-multiplexed high-bit-rate signal. AODs based on high nonlinear fibres [1] and semiconductor optical amplifiers [2] have been demonstrated at $320 \mathrm{Gbit} / \mathrm{s}$. The first type offers the potential for ultrafast operation based on the femtosecondscale time-response of the Kerr nonlinearity, the switching response of which is limited by the pulse width of the control pulse and the walkoff between the signal and the control pulses owing to the fibre length. The latter is limited by the switching performance owing to residual slow recovery times and losses by optical filtering.

Interest in periodically-poled lithium niobate (PPLN) as an ultrafast switching device resides in the femtosecond-scale response of the $\chi^{(2)}$ nonlinearity, low noise, compactness and high conversion efficiency at low optical powers. A first demonstration using PPLN as an AOD has been carried out at $160 \mathrm{Gbit} / \mathrm{s}$ by exploiting a second-order cascaded nonlinear effect [3]. The control signal, located in the C-band, is first frequency-doubled by second-harmonic ( $\mathrm{SH})$ generation. Subsequently, the upconverted signal acts on the data pulses via difference-frequency generation (DFG) extracting the selected channel in the C-band. Nevertheless, the maximum allowed bit-rate is limited by the broadening effect induced on the control pulses owing to the group-velocity mismatch (GVM) between the fundamental wavelength and its SH. A second demonstration consisted of adding/dropping a $10 \mathrm{Gbit} / \mathrm{s}$ tributary from an aggregated $320 \mathrm{Gbit} / \mathrm{s}$ signal by exploiting the sum-/ difference-frequency generation and pump depletion effects [4] employing high optical powers. However, no characterisation of the PPLN as an AOD was carried out. In this Letter, we present a demultiplexing scheme based on sum-frequency generation (SFG) where the maximum allowed operating bit-rate is mainly controlled by the pulsewidth of the control pulse. The broadening effect introduced by GVM does not act on the control pulse but on the extracted channel. This scheme allows errorfree operation at $320 \mathrm{Gbit} / \mathrm{s}$ using moderate optical powers.

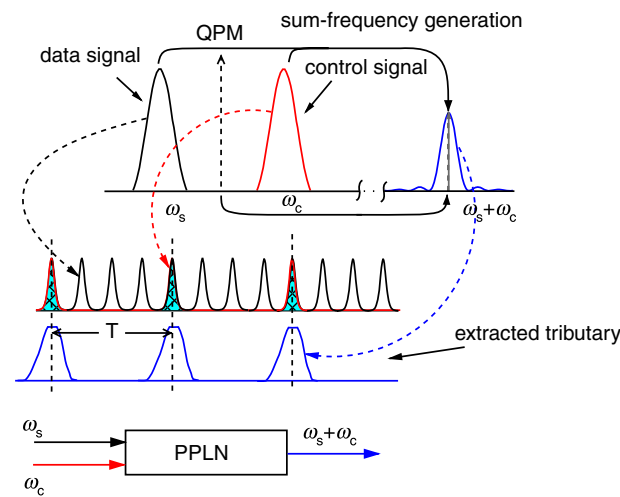

Fig. 1 SFG-based all-optical demultiplexing concept

Principle of operation: The wavelengths associated with the data and control signals, schematically shown in Fig. 1, are assigned to fulfil the conditions for SFG in the PPLN satisfying the relation $\lambda_{\mathrm{SH}}^{-1}=\lambda_{\mathrm{s}}^{-1}+\lambda_{\mathrm{c}}^{-1}$, where $\mathrm{s}$ and $\mathrm{c}$ denote the data and control signals, respectively, and $\lambda_{\mathrm{SH}}$ the wavelength of frequency-doubling of the PPLN. Normally, $\lambda_{\mathrm{SH}}$ is also called the quasi-phase matching (QPM) wavelength. The wavelengths ranges satisfying this relationship are within the transparency range of the material 0.35 to $\leq 4 \mu \mathrm{m}$. Both signals are coupled into the PPLN and by tuning an optical delay in the control signal path, a particular channel is selected. The interaction area between the signals is upconverted to the visible region and corresponds to the extracted channel. The extracted signal in question presents no intra-channel interference owing to the existing separation between pulses that corresponds to the period of the extraction rate Inter-channel interference is avoided by controlling the control pulse width. Finally, the extracted channels are detected by a photoreceiver to drive a bit-error-rate (BER) tester.

Experimental setup: A schematic of the experimental procedure is shown in Fig. 2. Optical pulses generated by a fibre modelocked laser (FMLL) with a pulse width of $1.5 \mathrm{ps}$ at $1550 \mathrm{~nm}$ and $40 \mathrm{GHz}$ repetition rate are amplitude modulated to form a $2^{7}-1$ return-to-zero on-off keying (RZ-OOK) PRBS stream. The pulses are compressed to $1 \mathrm{ps,}$ tuned to $1559 \mathrm{~nm}$ and multiplexed by a fibre-based interleaver to form the $320 \mathrm{Gbit} / \mathrm{s}$ OTDM signal. The control signal has a pulsewidth of $2.5 \mathrm{ps}$ at $1541 \mathrm{~nm}$ and $10 \mathrm{GHz}$ repetition rate. To resolve the data signal in the optical demultiplexer, the pulses were compressed to $1.2 \mathrm{ps}$ and tuned to $1533.6 \mathrm{~nm}$. The timing jitter of the control signal after pulse compression obtained from phase-noise measurements is $45 \mathrm{fs}$. The wavelengths of the data and control signals which satisfy SFG are coupled into the PPLN with the corresponding average power of 11 and $10 \mathrm{dBm}$. To select a particular channel of the OTDM signal, a tunable optical-delay line is placed in the path of the control signal. At the output of the PPLN, the extracted channels downconverted to $773.1 \mathrm{~nm}$ are detected by a $12 \mathrm{GHz}$ GaAs/pin photoreceiver for BER performance evaluation.

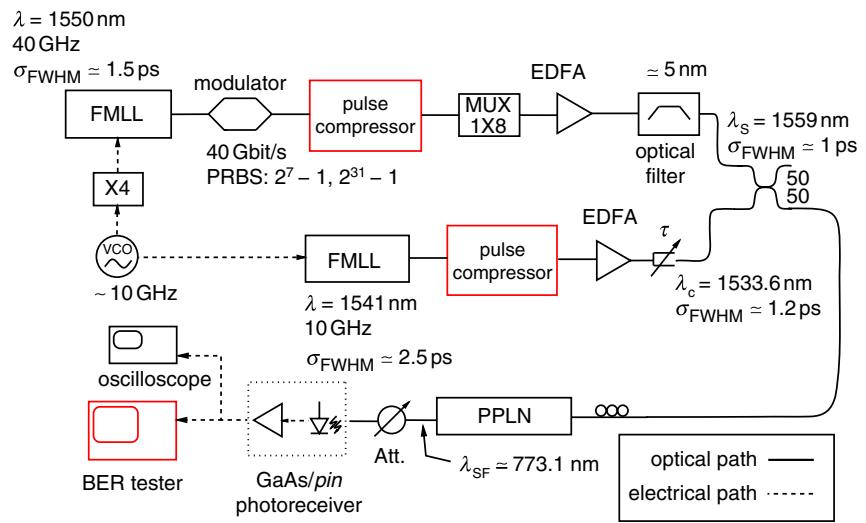

Fig. 2 PPLN-based all-optical demultiplexer
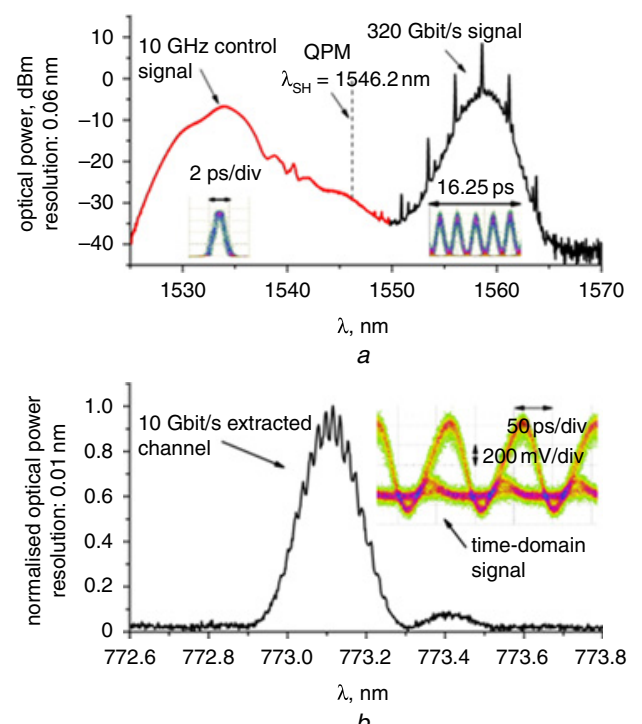

Fig. 3 Optical spectra at input of PPLN (Fig. 3a). $10 \mathrm{GHz}$ control signal and $320 \mathrm{Gbit} / \mathrm{s}$ data signal. Optical spectrum of $10 \mathrm{Gbit} / \mathrm{s}$ extracted channel (Fig. 3b)

Inset: Eye-diagram of extracted channel

The PPLN consists of a temperature-controlled and pigtailed $30 \mathrm{~mm}$ waveguide, the QPM of which at $52{ }^{\circ} \mathrm{C}$ peaks at $1546.2 \mathrm{~nm}\left(\lambda_{\mathrm{SH}}=\right.$ $773.1 \mathrm{~nm}$ ) with a normalised efficiency $\eta_{\text {norm }}=214 \% \mathrm{~W}^{-1}$. It holds a 
GVM of $2.5 \mathrm{fs} / \mathrm{mm}$ between signals in the C-band and $0.3 \mathrm{ps} / \mathrm{mm}$ between $\mathrm{SH}$ and C-band signals.

Results: The spectra of the signals entering into the PPLN are shown in Fig. 3a. The spectrum of the control pulse together with the spectrum of the $320 \mathrm{Gbit} / \mathrm{s}$ OTDM signal are placed in a conjugate-sided fashion with respect to the QPM wavelength. The corresponding wavelengths were assigned not only to satisfy the SFG process but also to reduce the amount of noise at the QPM wavelength. When the SFG process is satisfied, the extracted channel is selected by tuning the optical delay. This implies an overlapping or cross-correlation between the pulses of the control and data signals, downconverting the target channel to $\lambda_{\mathrm{SH}}$, the width of which is broadened from 1.2 to $10.2 \mathrm{ps}$ $(1.2 \mathrm{ps}+0.3 \mathrm{ps} / \mathrm{mm} \times 30 \mathrm{~mm})$ owing to the GVM. Since every $100 \mathrm{ps}$ (the period of the control signal) a pulse is extracted, no intrachannel crosstalk is revealed. Fig. $3 b$ shows the optical spectrum and time-domain trace of a $10 \mathrm{Gbit} / \mathrm{s}$ extracted channel. The width of the pulses is due to the combined effect of the impulse response of the photoreceiver and the oscilloscope. If the control pulses are not adequately compressed (as defined by the data bit-slot), inter-channel crosstalk will be experienced.

The BER performance of the PPLN-based demultiplexer is shown in Fig. 4. The circles illustrate error-free operation of a $10 \mathrm{Gbit} / \mathrm{s}$ single channel at $850 \mathrm{~nm}$ used as reference. The full and half-filled squares represent the best and worst case 320 -to- $10 \mathrm{Gbit} / \mathrm{s}$ demultiplexing performance. Error-free operation is achieved on all the channels with an average received optical power of $-16.4 \mathrm{dBm}$. This value corresponds to an average power penalty of $2 \mathrm{~dB}$ with respect to the reference. This penalty is due to a reduced OSNR and to the responsivity of the photoreceiver which is optimised for $850 \mathrm{~nm}$. The OSNR for the 320-to$10 \mathrm{Gbit} / \mathrm{s}$ case is $10.4 \mathrm{~dB}$ compared to $12 \mathrm{~dB}$ for the 160 -to- $10 \mathrm{Gbit} / \mathrm{s}$ case. BER curves for best and worst cases are also plotted in the same Figure. The attained average power penalty is less than $1.5 \mathrm{~dB}$. Finally, Fig. 5 shows the BER performance of $10^{-9}$ for 320 and $160 \mathrm{Gbit} / \mathrm{s}$ demultiplexed signals. Corresponding average optical powers of -16 and $-17 \mathrm{dBm}$ were attained.

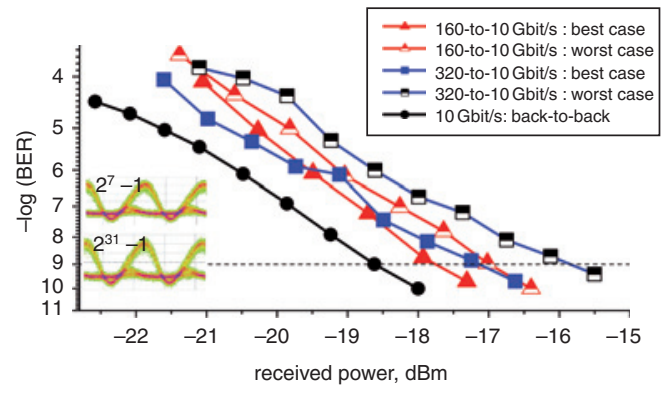

Fig. 4 BER curves of PPLN-based all-optical demultiplexer

Circles: single $10 \mathrm{Gbit} / \mathrm{s}$ channel; squares: 320 -to-10 Gbit/s demultiplexing-best case; half-filled squares: 320 -to-10 Gbit/s demultiplexing-worst case; triangles: 160 -to-10 Gbit/s - best case; half-filled triangles: 160 -to- $10 \mathrm{Gbit} / \mathrm{s}$ - worst case

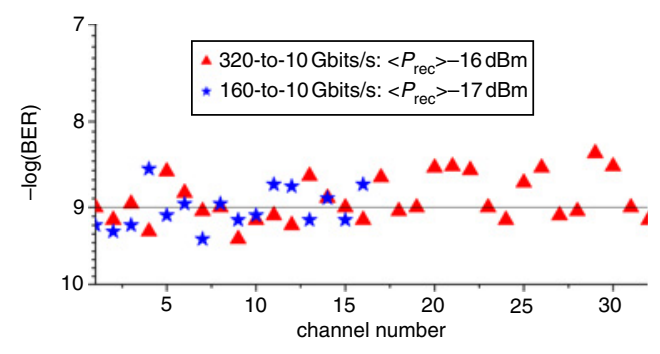

Fig. 5 BER performance of OTDM channels with fixed average power Stars: 160 -to-10 Gbit/s; triangles: 320 -to-10 Gbit/s

Conclusions: A successful all-optical demultiplexing scheme for 320-to-10 Gbit/s employing a periodically-poled lithium niobate waveguide is presented. By exploiting the sum-frequency generation nonlinear process, the bit-rate is limited by the pulsewidth of the control pulse. Error-free operation is achieved for all the channels attaining an average power penalty of $2 \mathrm{~dB}$. The results here outlined demonstrate the potential offered by PPLN waveguides in ultra-high-speed optical signal processing.

Acknowledgments: This work is supported by the European Commission project ICT-BOOM (www.ict-boom.eu) within the 7th Framework Program (FP7), Information and Communications Technologies (ICT). The work of A. Albores-Mejia is supported by CONACyT, Mexico.

(C) The Institution of Engineering and Technology 2010 8 January 2010

doi: $10.1049 / \mathrm{el} .2010 .0075$

One or more of the Figures in this Letter are available in colour online.

F. Gomez-Agis, C.M. Okonkwo, A. Albores-Mejia, E. Tangdiongga and H.J.S. Dorren (COBRA Research Institute, Eindhoven University of Technology, PO Box 513, NL-5600 MB, Eindhoven, The Netherlands)

E-mail: f.gomez-agis@tue.nl

\section{References}

1 Clausen, A.T., Siahlo, A.I., Seoane, J., Oxenlowe, L.K., and Jeppesen, P. ' 320 to $10 \mathrm{Gbit} / \mathrm{s}$ demultiplexing using a NOLM based on commercially available components', Electron. Lett., 2005, 41, pp. 265-266

2 Tangdiongga, E., Liu, Y., de Waardt, H., and Dorren, H.J.S.: 'Demultiplexing $160 / 320 \mathrm{~Gb} / \mathrm{s}$ to $40 \mathrm{~Gb} / \mathrm{s}$ using a single SOA assisted by an optical filter'. Optical Fiber Communication Conf. 2006 (OFC'06), Anaheim, CA, USA, paper OTuB5

3 Fukuchi, Y., Sakamoto, T., Taira, K., and Kikuchi, K.: 'All-optical timedivision demultiplexing of $160 \mathrm{Gbit} / \mathrm{s}$ signal using cascaded secondorder nonlinear effect in quasi-phase matched $\mathrm{LiNbO}_{3}$ waveguide device', Electron. Lett., 2003, 39, pp. 789-790

4 Bogoni, A., Wu, X., Fazal, I., and Willner, A.E.: 'Photonic processing of $320 \mathrm{Gbits} / \mathrm{s}$ based on sum-/difference-frequency generation and pump depletion in a single PPLN waveguide', Opt. Lett., 2009, 34, pp. $1825-1827$ 